\title{
Generation of embryonic stem cell lines from mouse blastocysts developed in vivo and in vitro: relation to Oct-4 expression
}

\author{
S Tielens, B Verhasselt ${ }^{1}$, J Liu ${ }^{2}$, M Dhont ${ }^{2}$, J Van Der Elst ${ }^{2}$ and M Cornelissen \\ Department of Anatomy, Embryology, Histology and Medical Physics, Ghent University, L. Pasteurlaan 2, B-9000 \\ Ghent, Belgium, ' Department of Clinical Chemistry, Microbiology and Immunology, Ghent University, De Pintelaan \\ 185, B-9000 Ghent, Belgium and ${ }^{2}$ Infertility Centre, Department of Obstetrics and Gynaecology, Ghent University \\ Hospital, De Pintelaan 185, B-9000 Ghent, Belgium
}

Correspondence should be addressed to M Cornelissen; Email: ria.cornelissen@ugent.be

\begin{abstract}
Embryonic stem (ES) cells are the source of all embryonic germ layer tissues. Oct-4 is essential for their pluripotency. Since in vitro culture may influence Oct-4 expression, we investigated to what extent blastocysts cultured in vitro from the zygote stage are capable of expressing Oct-4 and generating ES cell lines. We compared in vivo with in vitro derived blastocysts from B6D2 mice with regard to Oct-4 expression in inner cell mass (ICM) outgrowths and blastocysts. ES cells were characterized by immunostaining for alkaline phosphatase (ALP), stage-specific embryonic antigen-1 (SSEA-1) and Oct-4. Embryoid bodies were made to evaluate the ES cells' differentiation potential. ICM outgrowths were immunostained for Oct-4 after 6 days in culture. A quantitative real-time PCR assay was performed on individual blastocysts. Of the in vitro derived blastocysts, $17 \%$ gave rise to ES cells vs $38 \%$ of the in vivo blastocysts. Six-day old outgrowths from in vivo developed blastocysts expressed Oct-4 in $55 \%$ of the cases vs $31 \%$ of the in vitro derived blastocysts. The amount of Oct-4 mRNA was significantly higher for freshly collected in vivo blastocysts compared to in vitro cultured blastocysts. In vitro cultured mouse blastocysts retain the capacity to express Oct-4 and to generate ES cells, be it to a lower level than in vivo blastocysts.
\end{abstract}

Reproduction (2006) 132 59-66

\section{Introduction}

The isolation of mouse embryonic stem (ES) cells from the inner cell mass (ICM) of the developing blastocyst was first described over 20 years ago (Evans \& Kaufman 1981, Martin 1981). ES cells have found a number of important applications in basic research opening the door to potential applications in drug discovery and cell replacement medicine (Smith 1998, Solter \& Gearhart 1999). These aspirations for biotechnological and medical exploitation will require efficient derivation of stable pluripotent stem cell lines (Smith 2001).

The protocols for ES cell line derivation are relatively straightforward; the starting material is either dissociated morulae (Eistetter 1989), intact blastocysts (Evans \& Kaufman 1981), or the ICM (Martin 1981). The long-time maintenance of mouse ES cells is achieved in the presence of a feeder cell layer and/or leukemia inhibitory factor (LIF) (Williams et al. 1988). Mouse ES cells are pluripotent embryo-derived cells with a large clear nucleus containing one or more prominent nucleoli and little cytoplasm. They are characterized by high levels of intracellular alkaline phosphatase (ALP), presentation of specific cell surface glycoproteins such as the stage-specific embryonic antigen (SSEA)-1 (Solter \& Knowles 1978), presence of the transcription factor Oct4 (Schöler et al. 1989), a high telomerase activity (Thomson et al. 1998), and a short G1 phase of the cell cycle (Rohwedel et al. 1996). These properties, except the presence of Oct-4, are characteristic of, but not specific for, pluripotent stem cells. Other essential characteristics include growth as multicellular colonies, normal and stable karyotypes, prolonged undifferentiated proliferation, and the potential to differentiate into derivatives of all three embryonic germ layers even after prolonged culture (Shamblot et al. 1998, Thomson et al. 1998). Pluripotent stem cell lines sharing most of these characteristics have also been reported from chicken, mink, hamster, pig, rhesus monkey, common marmoset (Shamblot et al. 1998), and man (Thomson et al. 1998).

Although the derivation of ES cells from certain mouse strains is relatively straightforward, the maintenance of pluripotency during and after derivation is often less successful (Buehr \& Smith 2003). According to Evans \& Kaufman (1981), the success might depend on three 
critical factors: (1) the exact stage at which pluripotent cells, capable of growth in tissue culture exist in the embryo; (2) explantation of a sufficiently large number of these precursor cells from the embryo; and (3) culture conditions most conducive to multiplication rather than differentiation of these embryonic cells. Oct-4 is expressed only in pluripotent lineages and is considered a key factor in maintenance of pluripotency in vivo and in vitro (Niwa 2001).

Mouse Oct-4 (also called Oct-3 and NF-A3) is a 352 amino acid protein belonging to Class $\mathrm{V}$ of Pit-Oct-Unc family that regulates the expression of target genes by binding to the octamer motif ATGCAAAT within their promoter or enhancer regions (Herr \& Cleary 1995). Oct-4 has a unique pattern of RNA expression, which suggests a role in the regulation of early embryonic events. Oct- 4 expression patterns in the mouse suggest that Oct-4 is involved in the initial formation, selfrenewal, and maintenance of pluripotent cells (Nichols et al. 1998, Niwa 2001). At the blastocyst stage, Oct-4 protein expression becomes restricted to the cells of ICM (Pesce \& Shöler 2001) but is downregulated, however, during differentiation of these cells. Oct-4 expression is further restricted to primordial germ cells after day 8 of gestation (Rosner et al. 1990, Schöler et al. 1990). In vitro, expression of Oct-4 has also been confirmed in other mouse pluripotent cells, undifferentiated ES cells, embryonal carcinoma (EC) cells, and embryonic germ cells (Niwa et al. 2000, Tanaka et al. 2002). Loss of pluripotency on spontaneous or induced differentiation has been correlated with progressive loss of Oct-4 expression. The expression of Oct-4 becomes downregulated in ES and EC cells upon exposure to retinoic acid at concentrations that induce differentiation (AbdelRahman et al. 1995). Even more, the rapid loss of Oct-4 during culture of rodent blastocysts was a limiting factor in deriving pluripotent ES cell lines (Buehr et al. 2003).

Since in vitro culture may be influencing Oct-4 expression, we wanted to investigate to which extent blastocysts cultured in vitro from the zygote stage are capable of expressing Oct-4 and generating ES cell lines. In the present study, we describe the establishment and characterization of mouse ES cells derived from in vivo and in vitro cultured blastocysts with respect to ALP, SSEA-1, and Oct-4 expression and their capacity to differentiate in cells of the three germ layers. We studied the presence of Oct-4 in the outgrowths of these blastocysts after 6 days in culture. The levels of Oct- 4 transcripts between in vivo and in vitro developed blastocysts were compared.

\section{Materials and Methods}

\section{Animals}

Hybrid B6D2 (C57Bl/6×DBA) F1 mice (Charles River Laboratories, Brussels, Belgium) were used in this study with ethical approval from the Animal Research Ethical Committee, Ghent University Hospital. All animals were kept in temperature- and light-controlled rooms. B6D2F1 mice were stimulated to obtain either in vivo blastocysts or zygotes for further in vitro culture till the blastocyst stage. Female hybrids (6-10 weeks) were superovulated with an injection of $5 \mathrm{IU}$ equine chorionic gonadotrophin (Folligon, Intervet, Turnhout, Belgium) followed 46-48 h later with an injection of 5 IU human chorionic gonadotropin (hCG, Chorulon, Intervet, Turnhout, Belgium). Injected females were placed with B6D2 males and mating was confirmed the following morning by the presence of a vaginal plug.

Embryo age is given in hours or days post hCG injection (p.i.).

\section{Collection of mouse zygotes and blastocysts}

Females were sacrificed by cervical dislocation, $22 \mathrm{~h}$ after hCG, and zygote cumulus complexes were isolated out of the swollen ampullae. Zygotes were denuded by a brief exposure to hyaluronidase (200 IU), washed thoroughly and the fertilized zygotes were cultured in groups of 10 in $60 \mu \mathrm{l}$ drops of potassium simplex optimized medium (KSOM) in $60 \mathrm{~mm}$ dishes covered with light mineral oil in an atmosphere of $5 \% \mathrm{CO}_{2}$ in air at $37^{\circ} \mathrm{C}$.

The KSOM medium (Erbach et al. 1994) was prepared in the laboratory, had a low-glucose content $(0.2 \mathrm{mM})$, was supplemented with $4 \mathrm{mg} / \mathrm{ml}$ BSA and had an osmolarity of $265 \mathrm{mOsm}$. Freshly prepared media were stored at $4{ }^{\circ} \mathrm{C}$ and were used for up to 1 month.

They became blastocysts 4.5 days p.i. The in vivo grown blastocysts were collected from females killed on day 3.5 p.i. whose uteri were flushed with M2 medium (Sigma).

\section{Embryonic outgrowths and ES cell line derivation}

Blastocysts derived from cultured zygotes were collected at 4.5 days p.i. and the in vivo blastocysts at 3.5 days p.i. The blastocysts were initially explanted individually on a feeder layer of mytomicin C-inactivated confluent mouse embryonic fibroblasts (MEFs) in a 96-well plate (Greiner, Wemmel, Belgium). MEF were obtained from 12.5 days postcoitus mouse embryos as described in detail elsewhere (Schoonjans et al. 2003).

Culture of blastocyst outgrowths on MEF was done in Dulbecco's modified eagle medium supplemented with $0.1 \mathrm{mM} \beta$-mercaptoethanol, 10\% Knockout serum replacement, $0.1 \mathrm{mM}$ nonessential amino acids (Gibco $\mathrm{BRL}$, Life technologies) and $1000 \mathrm{IU} / \mathrm{ml}$ LIF (ESGRO, Chemicon International, Asse-Relegem, Belgium). After culture for 6 days on MEF, ICM outgrowths were disaggregated by trypsinization and grown further on new feeder layers. After disaggregation, the cells were plated in culture. Medium was changed daily and the cells growing in colonies, designated as mouse ES cells, 
were split every 2 days and passaged by replating onto dishes with fresh MEF.

\section{Generation of embryoid bodies (hanging drop method)}

Embryoid bodies (EBs) were prepared using the 'hanging drop' method. Once secondary ES cell cultures reached confluency, the ES cell colonies were disaggregated using trypsin and resuspended in differentiation medium ( $\alpha$ MEM containing $10 \%$ FCS and $100 \mu \mathrm{M}$ ascorbic acid (Sigma)) at a concentration of 40000 cells $/ \mathrm{ml}$. Twenty microliter drops of the suspension were placed on the lid of a $100 \mathrm{~mm}$ plastic culture dish (Greiner). The lid was turned upside down and placed on the bottom part which was filled with PBS and then incubated at $37^{\circ} \mathrm{C}$ with $5 \% \mathrm{CO}_{2}$ for 2 days.

The EBs were transferred on day 3 of culture into another plastic culture dish containing $8 \mathrm{ml}$ differentiation medium. EBs were further cultivated in suspension for 3 days to obtain well-formed EBs. At day 5, the resulted EBs were plated individually into 24-well tissue culture plates (Greiner) to study differentiation into the three germ layers.

\section{Immunostaining}

\section{Stem cell markers}

Oct-4. Embryonic outgrowths were fixed with acetone $\left(-20^{\circ} \mathrm{C}\right)$ during $5 \mathrm{~min}$. The outgrowths were sampled for both kinds of matured blastocysts. Nonspecific staining was blocked with $2 \%$ BSA, $0.2 \%$ Tween and anti-rabbit serum in PBS during 30 min. The outgrowths were incubated overnight with the primary mouse $M A B$ $(1: 50)$ raised against a recombinant protein corresponding to amino acid 1-134 of human Oct-4 (C10) (sc-5279) (Santa Cruz Biotechnology, Santa Cruz, CA, USA). After extensive washing, outgrowths were exposed to biotinylated rabbit anti-mouse secondary antibody. After reaction with the horse radish peroxidase (HRP)-labeled streptavidin, localization of antigens was visualized by diaminobenzidine (DAB).

The same procedure was performed on the cell lines to characterize them as ES cells.

Alkaline phosphatase. ALP expression was determined by staining with a diagnostic kit ALP substrate kit III (Vector Laboratories, Burlingame, CA, USA) according to the manufacturer's instructions.

Stage-specific embryonic antigen-1. Embryonic cells grown on feeder layers on plastic coverslips were fixed during 5 min with acetone $\left(-20^{\circ} \mathrm{C}\right)$, washed with PBS, incubated with blocking serum containing $2 \%$ BSA, $0.2 \%$ Tween and anti-goat serum during $30 \mathrm{~min}$ and then incubated with the primary MAB MC-480 (Hybridoma Data Bank, University of lowa, lowa City, IA, USA) in a humidified chamber overnight at $4{ }^{\circ} \mathrm{C}$. The cultures were washed with PBS, and incubated with goat anti-mouse IgM antibody conjugated with fluorescein isothiocyanate (Sigma) for $1 \mathrm{~h}$, washed with PBS, embedded in glycerol-containing propidium iodide, and investigated by a confocal laser scanning microscopy system (Radiance 2100 blue laser diode, BioRad). All incubations were carried out in the presence of $2 \%$ BSA.

\section{Differentiation markers}

To confirm that the ES cells were able to differentiate into three germ layers, we performed immunohistochemistry on the plated EBs. We used the markers alpha fetoprotein (AFP) for endodermal cells, $\alpha$-smooth muscle actin for mesodermal cells and neurofilament for ectodermal cells. After 4 weeks of differentiation, the EBs were fixed with acetone $\left(-20^{\circ} \mathrm{C}\right)$ during $5 \mathrm{~min}$. Nonspecific staining was blocked with $2 \%$ BSA, $0.2 \%$ Tween and anti-rabbit serum in PBS during $30 \mathrm{~min}$. The EBs were incubated for $2 \mathrm{~h}$ with the primary goat polyclonal antibody AFP (1:100) (sc-8108) (Santa Cruz Biotechnology), primary monoclonal mouse anti-human smooth muscle actin (1:200) (DakoCytomation M0635) or with the primary anti-swine neurofilament protein (1:100) (DakoCytomation M0726). After extensive washing, EBs were exposed to biotinylated goat antimouse or rabbit anti-mouse secondary antibody. After the reaction with HRP-labeled streptavidin, localization of antigens was visualized by DAB.

\section{RNA extraction and CDNA preparation}

Three maturation conditions of blastocysts with regard to Oct-4 expression were compared: (1) blastocysts obtained from cultured zygotes (in vitro 4.5 days p.i.), (2) blastocysts directly flushed from the uterus (in vivo 3.5 days p.i.), and (3) blastocysts flushed from the uterus after 3.5 days p.i. in vivo and cultured for 1 additional day to reach the same p.i. time as needed for the in vitro development (in vivo 4.5 days p.i.).

The total RNA was extracted from individual blastocysts using the Absolutely RNA Nanoprep Kit (Stratagene, La Jolla, CA, USA). The total RNA samples were subjected to DNase digestion.

The cDNAs were prepared using the SuperScript First Strand Synthesis System for RT-PCR (Invitrogen) according to the manufacturer's instructions.

\section{Quantitative real-time RT-PCR}

Primers used for PCR amplification were purchased from Eurogentec (Liège, Belgium). The sequences are listed in Table 1.

Real-time PCR was performed in a $25 \mu \mathrm{l}$ reaction mixture comprising $5 \mu \mathrm{l}$ CDNA (equivalent to one-fourth of total RNA) containing a final concentration of $15 \mathrm{nM}$ 
Table 1 Sequences of primers used for PCR amplification of Oct- 4 and GAPDH.

\section{Oct-4}

Sense: 5'-ATGTTTCTGAAGTGCCCGAA- $3^{\prime}$

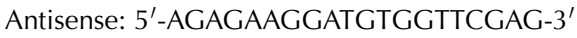

GADPH

Sense: $5^{\prime}$-TCACCACCATGGAGAAGGC-3'

Antisense: 5'-GCTAAGCAGTTGGTGGTGCA-3'

oligonucleotide primers, $3.5 \mathrm{mM} \mathrm{MgCl}_{2}, 0.2 \mathrm{mM}$ dNTPs, and $0.025 \mathrm{U} / \mu \mathrm{l}$ Hot GoldStar enzyme (Eurogentec) measured with a Perkin Elmer ABI Prism 7700 Sequence Detection System (Applied Biosystems, Foster City, CA, USA).

Reactions were incubated for $10 \mathrm{~min}$ at $95^{\circ} \mathrm{C}$, followed by 50 cycles of a two-step amplification procedure consisting of annealing/extension at $60{ }^{\circ} \mathrm{C}$ for $1 \mathrm{~min}$ and denaturated for $15 \mathrm{~s}$ at $95^{\circ} \mathrm{C}$. In each run, dilution series of cDNA from a B6D2 ES cell line were amplified to serve as a standard curve for the calculation of relative quantities of the target gene to the housekeeping gene. As negative controls water and mouse fibroblasts cDNA and as positive controls the B6D2 ES cell line cDNA and gDNA were used.

\section{Statistical analysis}

Data concerning the real-time PCR are expressed as median and interquartile. The Mann-Whitney $U$ test was used for comparisons between unpaired groups. $P$-values less than 0.01 were considered statistically significant.

\section{Results}

\section{Number of collected in vitro vs in vivo blastocysts}

It was possible to harvest about 20 zygotes $22 \mathrm{~h}$ p.i. from each superovulated mouse. More than $80 \%$ of these zygotes become blastocysts in our in vitro conditions. In contrast, when the uterus is flushed from a superovulated mouse at 3.5 days p.i., a high variability in blastocyst yield is noticed. Despite the presence of a vaginal plug, we could not flush blastocysts from a large number of mice.

\section{Establishment and characterization of embryonic stem cell lines}

The efficiency to derivate ES cell lines from in vivo blastocysts vs blastocysts cultured in vitro from zygotes is summarized in Table 2. The number of cell lines obtained from the in vivo blastocysts is about twice the number obtained from the in vitro blastocysts. The cell lines designated as ES cell lines grew in small compact dense colonies. Stainings performed at passage 8 were positive for ALP, SSEA-1, and Oct-4. The histochemical detection of ALP, the immunohistochemical detection of SSEA-1 and Oct-4 are shown in Fig. 1.
Table 2 Efficiency of embryonic stem (ES) line derivation from B6D2 blastocysts.

\begin{tabular}{lcc}
\hline Starting material & $\begin{array}{c}\text { Total number of } \\
\text { explants }\end{array}$ & $\begin{array}{c}\text { Number giving ES } \\
\text { lines }(\%)\end{array}$ \\
\hline In vitro blastocyst & 24 & $4(17)$ \\
In vivo blastocyst & 24 & $9(38)$ \\
\hline
\end{tabular}

The histochemical detection of the differentiation markers in the three germlayers on the EBs, i.e. neurofilament (ectoderm), AFP (endoderm) and $\alpha$-smooth muscle actin (mesoderm) are shown in Fig. 2.

\section{Expression of Oct-4 protein in blastocyst outgrowths at 3 and 6 days in culture}

Approximately, 1-2 days after a blastocyst plating culture was started, the embryo attached to the substrate. After 3 days of outgrowth culture, $80 \%$ of the ICM outgrowths expressed Oct-4. By day 6, the time point of first trypsinization, the number of outgrowths containing positive cells was clearly lower; $55 \%$ of the outgrowths retained Oct-4 positive cells in the in vivo derived blastocysts compared to $31 \%$ for the in vitro derived blastocysts (Table 3 ). The decrease of Oct-4 expression was more pronounced in outgrowths originating from the in vitro rather than the in vivo blastocysts. An Oct-4 positive outgrowth of 3 days and a positive and negative outgrowth of 6 days are shown in Fig. 3.

\section{Determination of the amount of Oct-4 mRNA in individual in vitro and in vivo blastocysts}

Expression of Oct-4 mRNA in in vitro and in in vivo maturated blastocysts was quantitatively assessed in individual blastocysts by real-time RT-PCR, relative to GAPDH house-keeping gene expression. The in vivo obtained blastocysts were analyzed at the time they were flushed ( 3.5 days p.i.) and after 1 day in culture ( 4.5 days p.i.) to obtain the same p.i. time point as for the in vitro cultured blastocysts.

In the 3.5 days p.i. in vivo blastocysts, the Oct-4 mRNA expression was significantly higher compared to the in vitro cultured blastocysts (see Fig. 4).

No statistically significant difference was found between the blastocysts cultured in vitro from the zygote stage and in vivo blastocysts collected at 3.5 days p.i., which were cultured for 1 extra day in vitro.

\section{Discussion}

Pluripotent ES cells that can give rise to all embryonic tissues are localized in the ICM of blastocysts. The expression of the transcription factor Oct-4 in ES cells is essential in maintenance of pluripotency. Since in vitro 

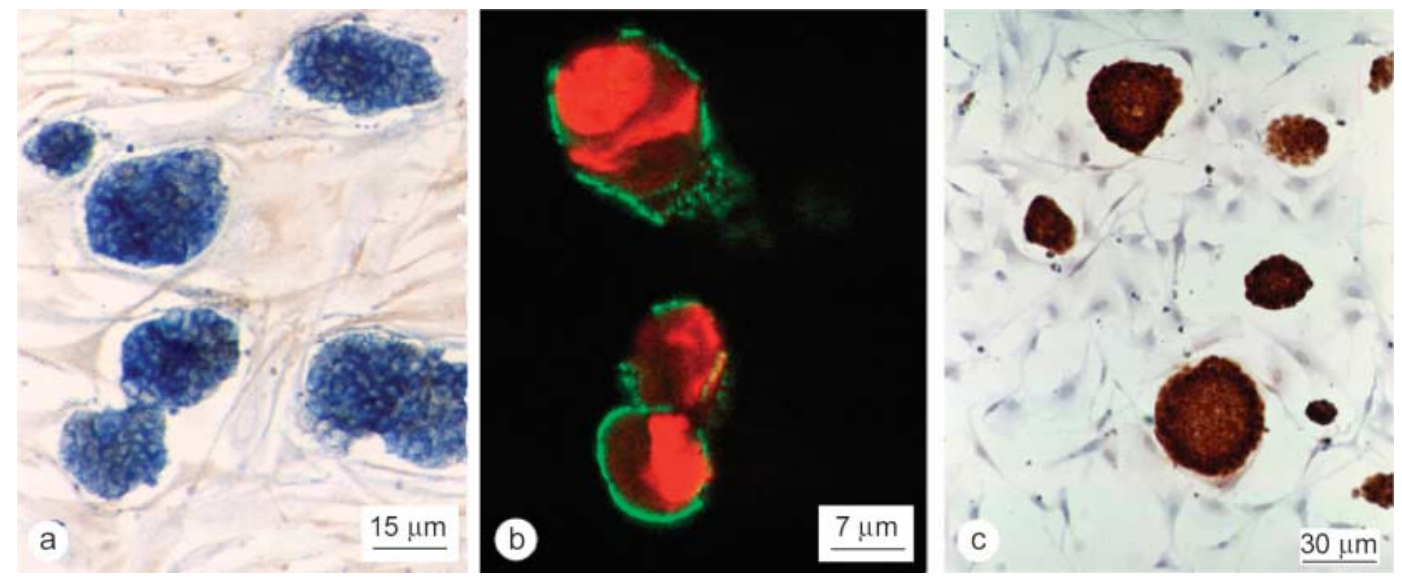

Figure 1 Characterization of mouse embryonic stem (ES) lines established from blastocysts: (a) Alkaline phosphatase activity: ES cells are stained in blue; differentiated ES cells and the MEFs are stained in brown (vimentine/cytokeratine), (b) stage-specific embryonic antigen-1 (SSEA-1) staining: nuclei are red (propidium iodide) and the carbohydrate SSEA-1 green (c) Oct-4 staining: the ES cell colonies are stained in brown and the MEFs are purple (hematoxyline counter staining).

culture may be influencing Oct-4 expression, we investigated to what extent blastocysts cultured in vitro from the zygote stage are capable of expressing Oct-4 and of generating ES cell lines. We compared the efficiency of ES cell line derivation as well as the pattern of Oct-4 expression in blastocysts and ICM outgrowths in freshly collected in vivo blastocysts vs in vitro cultured blastocysts. Our results show that Oct-4 is expressed in in vitro cultured blastocysts and their outgrowths and that in vitro cultured blastocysts can generate ES cells, but to a lesser extent than in vivo collected blastocysts.

In spite of the widespread use of in vitro developed blastocysts, surprisingly little is known about their potential to give rise to ES cell lines. Nevertheless, the study of a model starting of in vitro developed blastocysts can have several advantages. First of all, the number of blastocysts, obtained from zygotes developed in vitro is higher than the number of blastocysts flushed in vivo.
In our experiments, about 20 zygotes were collected per superovulated mouse. More than $80 \%$ of the zygotes developed to the blastocyst stage following culture in vitro, confirming their high developmental competence. In contrast, high variability is noticed in the yield of blastocysts flushed after in vivo development. Secondly, in vitro cultured blastocysts will be the only possible source for ES cells in human. Flushing of blastocysts in vivo is not an option in humans, but blastocysts can fairly easily be obtained through the techniques of assisted reproduction developed for infertility treatment. Even more, when therapeutic cloning is ever to be used clinically there is the need for successfully and routinely establishing cell lines from cloned blastocysts.

Our results showed a lower efficiency in establishing ES cell lines from in vitro vs in vivo developed blastocysts (17 vs $38 \%$ ). The results for in vivo developed blastocysts
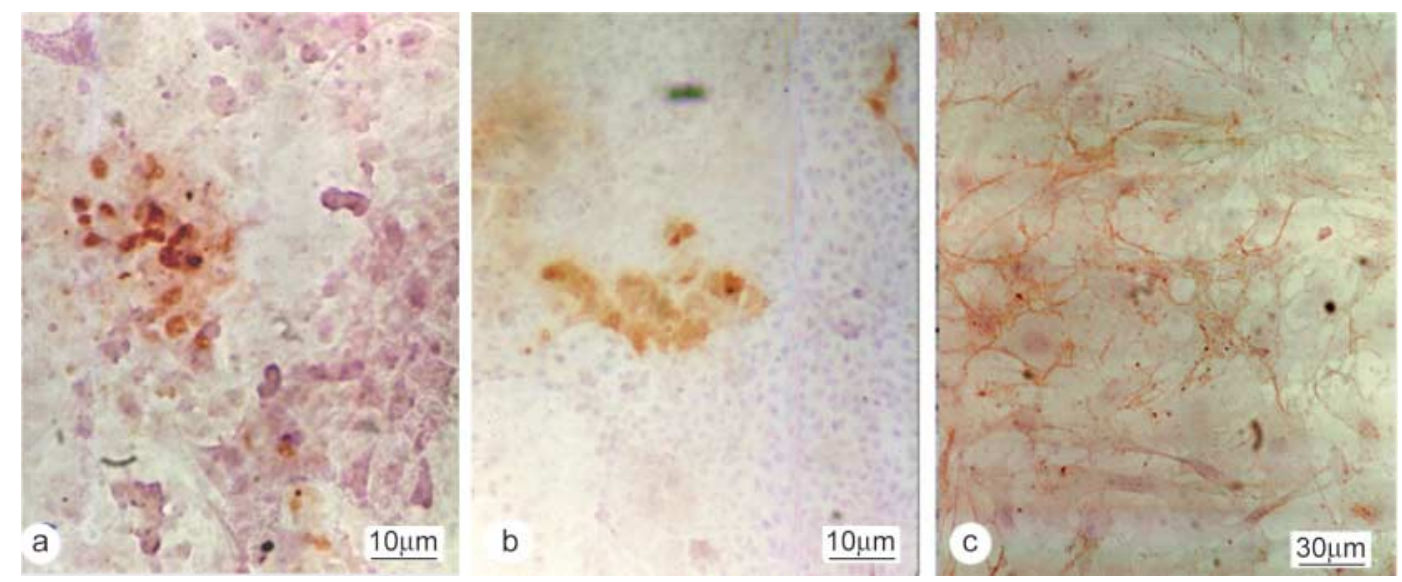

Figure 2 Characterization of mouse ES lines: the histochemical detection of the differentiation markers in the three germlayers on the EBs, i.e. (a) neurofilament (ectoderm), (b) alpha fetoprotein (endoderm) and (c) alpha smooth muscle actin (mesoderm). 
Table 3 Expression of Oct-4 protein in outgrowths of blastocysts from in vitro and in vivo developed blastocysts after 6 days in culture.

\begin{tabular}{lll}
\hline Days in culture & \% of Oct-4 positive outgrowths \\
\hline & In vivo blastocysts & In vitro blastocysts \\
3 & $73(n=11)$ & $82(n=11)$ \\
6 & $55(n=18)$ & $31(n=16)$ \\
\hline
\end{tabular}

are strain dependent (Kawase et al. 1994) and our results fall within the range published for other mouse strains. For example, about $30 \%$ of strain, 129 blastocysts cultured according to standard derivation procedures will give rise to ES cells (Brook \& Gardner 1997, Robertson 1987).

The criteria used in our study to characterize ES cell lines were the expression of ALP, SSEA-1, and Oct- 4 and their possibility to give rise to cells of the three germlayers. These properties are most commonly used to characterize pluripotent ES cells (Vassilieva et al. 2000). Among these markers, Oct-4 appears to be indispensable for pluripotent capacity both in the embryo and in the ES cell lines (Nichols et al. 1998, Niwa et al. 2000). It is assumed that continuous expression of Oct-4 in precursor cells is necessary throughout derivation of ES cell lines (Buehr \& Smith 2003). For this reason, we checked whether the lower efficiency of ES cell derivation for in vitro developed blastocysts may be related to lower Oct-4 expression patterns. We tracked expression of Oct-4 in ICM outgrowths. Staining of Oct-4 was performed after 6 days in culture. This is the time point of trypsinization of the outgrowths for ES cell line derivation. Nearly, 32 and $55 \%$ of the outgrowths were Oct- 4 positive for the in vitro and in vivo matured blastocysts respectively. It can be noticed that only about half of Oct-4 positive outgrowths gave rise to ES cell lines. This may be related to loss of Oct-4 positive cells during and after the first trypsinization, a critical and difficult step in stem cell derivation. Also, the level of expression of Oct-4 is likely to be critical. Although the outgrowths are considered as Oct-4 positive by immunohistochemistry, differences in expression levels between the positively stained outgrowths can exist. It is known that the level of Oct-4 is decisive for either pluripotency or differentiation (Niwa et al. 2000). It is described that blastocysts and outgrowths with low or absent Oct-4 are not able to give rise to ES cell lines (Boiani et al. 2002). Other studies show that subtle variations in the level of Oct-4, not only below but also above the normal level can result in differentiation. Also, culturing blastocysts under standard ES cell derivation conditions can cause a decline in the number of Oct-4 expressing cells (Buehr \& Smith 2003). In our experiments, we observed a decrease in Oct-4 expression during the culture period preceding the trypsinization time point, while after 3 days of culture still $80 \%$ of all the outgrowths expressed Oct- 4 . According to Buehr \& Smith (2003), this rapid loss of Oct-4 may underlie the difficulties often encountered in ES cell derivation. If, as seems likely true, ES cells are derived directly from the Oct-4 expressing cells, the keys to successful derivation may lie in conditions or treatment that allow to extend the time window of Oct-4 expression.

It was also considered interesting to investigate the amounts of Oct- 4 in our starting material for ES cell line derivation, the in vivo and in vitro developed blastocysts. We performed real-time PCR on individual blastocysts. For the in vitro obtained blastocysts, PCR was performed 4.5 days p.i.; for the in vivo obtained blastocysts, PCR was done on freshly obtained blastocysts (3.5 days p.i.) and on blastocysts developed for 4.5 days p.i. Blastocysts developed in vitro from the zygote or developed in vivo did not show the same maturation stage after the same p.i. time period. To reach the expanded blastocyst stage starting from zygotes, 4.5 days p.i. were needed. At this time point, nearly all embryos reached the
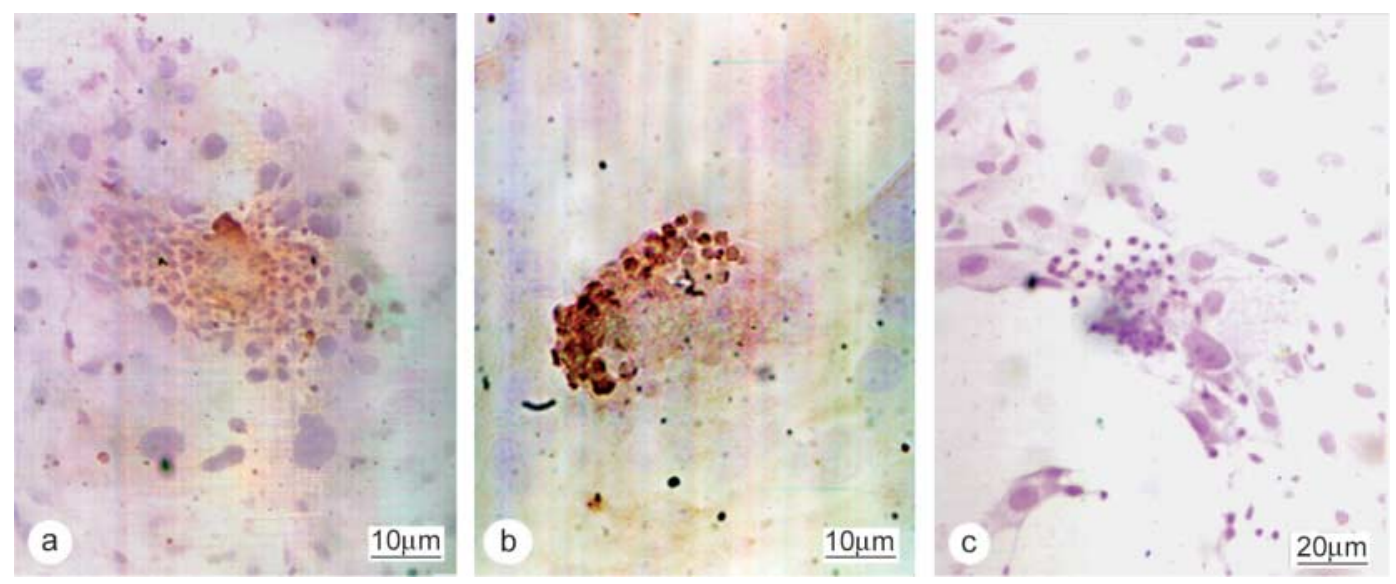

Figure 3 Expression of endogenous Oct-4 in blastocyst outgrowths. (a) Positive Oct-4 expression in the outgrowth after 3 days in culture. (b) Positive Oct-4 expression in the outgrowth after 6 days of culture. (c) Negative Oct-4 expressing in the outgrowth after 6 days of culture. 


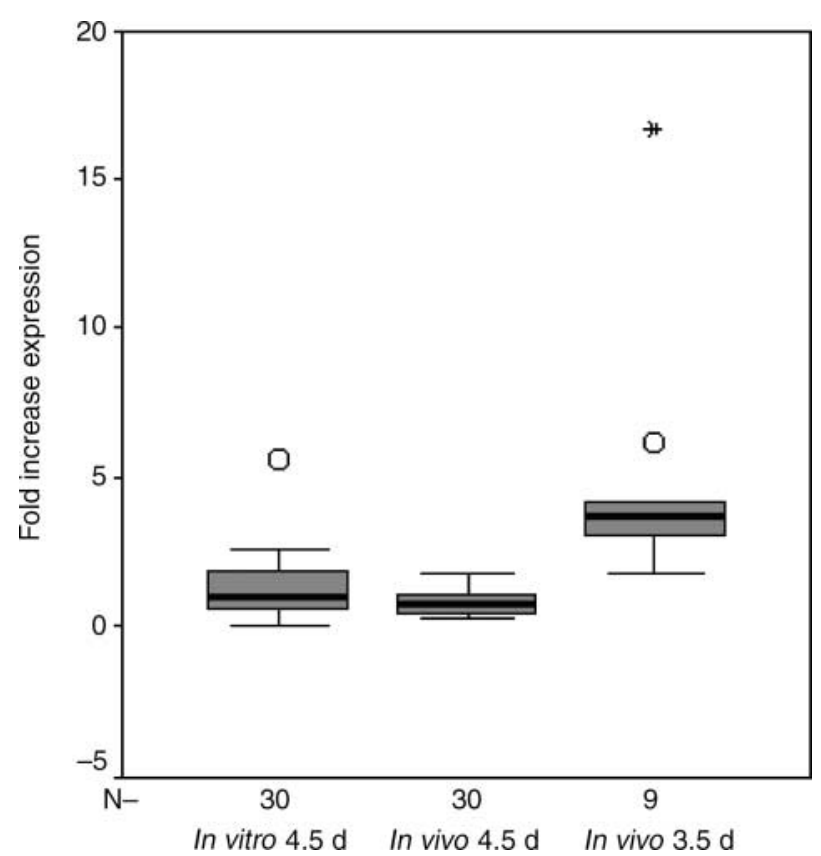

Figure 4 Quantification of Oct-4 mRNA with real-time RT-PCR (boxplot graph) in in vitro and in vivo matured blastocysts. Fold increase of relative expression level (in relation to GAPDH house-keeping gene) compared to median of in vitro 4.5 days.

expanded blastocyst stage (after 3.5 days p.i. only morulae and very early blastocysts were present in the in vitro culture condition). However, when we wanted to obtain blastocysts developed in vivo, only flushing after 3.5 days p.i. time resulted in a good yield which is a p.i. time commonly used to derive mouse ES cell lines from in vivo developed blastocysts (Hogan et al. 1994). At this time point, we observed a wide variation in maturation stages among the flushed embryos. Expanded blastocysts were selected for real-time PCR but also early blastocysts and morulae were present. After 1 day in culture (at day 4.5 p.i.), all embryos reached the expanded blastocyst stage. In order to explain this apparent growth retardation in vitro, we speculate that the oviduct secretes (an) essential growth factor(s) and/or amino acids needed by embryos for the activation of their embryonic genome to permit the subsequent development into healthy blastocysts and fetuses. These factors possibly explain the delay in development often observed in in vitro culture systems (Van der Auwera et al. 1999).

No significant differences in Oct-4 mRNA transcript levels were found between in vitro developed blastocysts 4.5 days p.i. and between 3.5 days p.i. blastocysts that were cultured in vitro for 1 day. In contrast, significantly higher Oct-4 levels were detected in the freshly obtained in vivo developed blastocyst ( 3.5 days p.i.). This suggests a rapid loss of Oct-4 expression in vitro. According to Kiessling et al. (1991), embryos that develop in vitro from the two-cell stage exhibit fewer total cells; the percent of cells in mitosis and the ratio of cells in the ICM to those in the trophoblast layer are the same as in in vivo embryos with the same cell number. This can suggest that the expression in Oct-4 in one cell of the ICM is higher in the in vivo blastocyst than in the in vitro maturated blastocyst, but this has to be confirmed by doing real time PCR on isolated ICM.

\section{Conclusion}

In vitro developed mouse B6D2 blastocysts retain Oct-4 mRNA transcript expression in individual blastocysts, Oct-4 expression in ICM outgrowths and the capacity to generate ES cell lines but all to a lower extent than in vivo developed blastocysts. These observations suggest that the success of ES cell derivation from in vitro developed blastocysts may be increased by searching culture conditions that allow to maintain Oct-4 expression.

\section{Acknowledgements}

The authors thank R Devos, B Heindryckx, S Lierman, L Pieters, L Schoonjans, K Smits, V Stove, and A Waeytens for their technical support. This work was supported by a grant from Ghent University (GOA project 2001, No 12050701 and BOF 2001 - project 01110301). B Verhasselt is a Senior Clinical Investigator of the Fund for Scientific Research - Flanders (Belgium) (Fwo Vlaanderen).

\section{References}

Abdel-Rahman B, Fiddler M, Rappolee D \& Pergament E 1995 Expression of transcription regulating genes in human preimplantation embryos. Human Reproduction 10 2787-2792.

Boiani M, Eckardt S, Schöler HR \& McLaughlin KJ 2002 Oct-4 distribution and level in mouse clones: consequences for pluripotency. Genes and Development 16 (Supplement 10) 1209-1219.

Brook FA \& Gardner RL 1997 The origin and efficient derivation of embryonic stem cells in the mouse. PNAS 94 5709-5712.

Buehr M \& Smith A 2003 Genesis of embryonic stem cells Philosophical Transactions: Biological Sciences. Royal Society London, B 358 1397-1402.

Buehr M, Nichols J, Stenhouse F, Mountford P, Greenhalgh CJ, Kantachuvesiri S, Brooker G, Mullins J \& Smith AG 2003 Rapid loss of Oct-4 and pluripotency in cultured rodent blastocysts and derivative cell lines. Biology of Reproduction 68 222-229.

Eistetter HR 1989 Pluripotent embryonal stem cell lines can be established from disaggregated mouse morulae. Development Growth and Differentiation 31 275-282.

Erbach GT, Lawitts JA, Papaioannou VE \& Biggers JD 1994 Differential growth of the mouse preimplantation embryo in chemically defined media. Biology of Reproduction 50 1027-1033.

Evans MJ \& Kaufman M 1981 Establishment in culture of pluripotent cells from mouse embryo. Nature 292 154-156.

Herr W \& Cleary MA 1995 The Pou domain: versatility in the transcriptional regulation by a flexible two-in-one DNA-binding domain. Genes and Development 9 1679-1693.

Hogan B, Beddington R, Constantini F \& Lacy E 1994 Manipulating the Mouse Embryo: A Laboratory Manual. Cold Spring Harbor Press. 
Kawase E, Suemori H, Takahashi N, Okazaki K, Hashimoto K \& Nakatsuji N 1994 Strain differences in establishment of mouse embryonic stem (ES) cell lines. International Journal of developmental Biology 38 385-390.

Kiessling AA, Davis HW, Williams CS, Sauter RW \& Harrison LW 1991 Development and DNA polymerase activities in cultured preimlantation mouse embryos: comparison with embryos developed in vivo. Journal of Experimental Zoology 258 34-47.

Martin GR 1981 Isolation of a pluripotent cell line from early mouse embryos cultured in medium conditioned by teratocarcinoma cells. PNAS 78 7634-7638.

Nichols J, Zevnik B, Anastassiadis K, Niwa H, Klewe-Nebenius D, Chambers I, Scholer H \& Smith A 1998 Formation of pluripotent stem cells in the mammalian embryo depends on the POU transcription factor Oct4. Cell 95 379-391.

Niwa H 2001 Molecular mechanism to maintain stem cell renewal of ES cells. Cell structure and function 26 137-148.

Niwa H, Miyazaki J \& Smith AG 2000 Quantitative expression of Oct3/4 defines differentiation, dedifferentiation, or self-renewal of ES cells. Nature Genetics 24 372-376.

Pesce M \& Shöler HR 2001 Oct-4: Gatekeeper in the beginnings of the mammalian development. Stem Cells 19 271-278.

Robertson EJ 1987 Embryo-derived Stem Cell Lines, Teratocarcinomas and Embryonic Stem Cells: A Practical Approach, Oxford, UK: IRL Press.

Rohwedel J, Sehlmeyer U, Shan J, Meister A \& Wobus AM 1996 Primordial germ cell derived mouse embryonic germ (EG) cells in vitro resemble undifferentiated stem cells with respect to differentiation capacity and cell cycle distribution. Cell Biology International 20 579-587.

Rosner MH, Vigano MA, Ozato K, Timmons PM, Poirier F, Rigby PWJ \& Staudt LM 1990 A POU-domain transcription factor in early stem cells and germ cells of the mammalian embryo. Nature 345 686-692.

Schöler HR, Hatzopoulos AK, Balling R, Suzuki N \& Gruss P 1989 A family of octamer specific proteins present during mouse embryogenesis: Evidence for germline-specific expression of an Oct factor. European Molecular Biology Organization Journal 8 2543-2550.

Schöler HR, Dressler GR, Balling R, Rohdewohld H \& Gruss P 1990 Oct-4: A germline-specific transcription factor mapping to the mouse t-complex. European Molecular Biology Organization Journal $92185-2195$.
Schoonjans L, Kreemers V, Danloy S, Moreadith RW, Laroche Y \& Collen D 2003 Improved generation of germline-competent embryonic stem cell lines from inbred mouse strains. Stem Cells 21 90-97.

Shamblot MJ, Axelman J, Wang S, Bugg EM, Littlefield JW, Donovan PJ, Blumenthal PD, Huggins GR \& Gearhart JD 1998 Derivation of pluripotentstem cells from cultured human primordial germ cells. PNAS 95 13726-13731.

Smith AG 1998 Cell therapy: in search of pluripotency. Current Biology 8 802-804.

Smith AG 2001 Embryo-derived stem cells: of mice and men. Annual Review of Cell and Developmental Biology 17 435-462.

Solter D \& Knowles BB 1978 Monoclonal antibody defining a stagespecific mouse embryonic antigen (SSEA-1). PNAS 75 5565-5569.

Solter D \& Gearhart J 1999 Putting stem cells to work. Science 283 1468-1470.

Tanaka TS, Kunath T, Kimber WL, Jaradat SA, Stagg CA, Usuda M, Yokota T, Niwa H, Rossant J \& Ko MS 2002 Gene expression profiling of embryo-derived stem cells reveals candidate genes associated with pluripotency and lineage specificity. Genome Research 12 1921-1928.

Thomson JA, Itskovitz-Eldor J, Shapiro SS, Waknitz MA, Swiergiel JJ, Marshall VS \& Jones MJ 1998 Embryonic stem cell lines derived from human blastocysts. Science 282 1145-1147.

Van der Auwera I, Pijnenborg R \& Koninckx PR 1999 The influence of in-vitro culture versus stimulated and untreated oviductal environment on mouse embryo development and implantation. Human Reproduction 14 2570-2574.

Vassilieva S, Guan K, Pich U \& Wobus AM 2000 Establishment of SSEA1 - and Oct-4-expression rat embryonic stem-like cell lines and effects of cytokines of the IL-6 family on clonal growth. Experimental Cell Research 258 361-373.

Williams RL, Hilton DJ, Pease S, Wilson TA, Stewart CL, Gearing DP, Wagner EF, Metcalf D, Nicola NA \& Gough NM 1988 Myeloid leuaemia inhibitory factor maintains the developmental potential of embryonic stem cells. Nature 336 684-687.

Received 15 July 2005

First decision 19 August 2005

Revised manuscript received 30 January 2006

Accepted 31 March 2006 